Provided for non-commercial research and education use. Not for reproduction, distribution or commercial use.

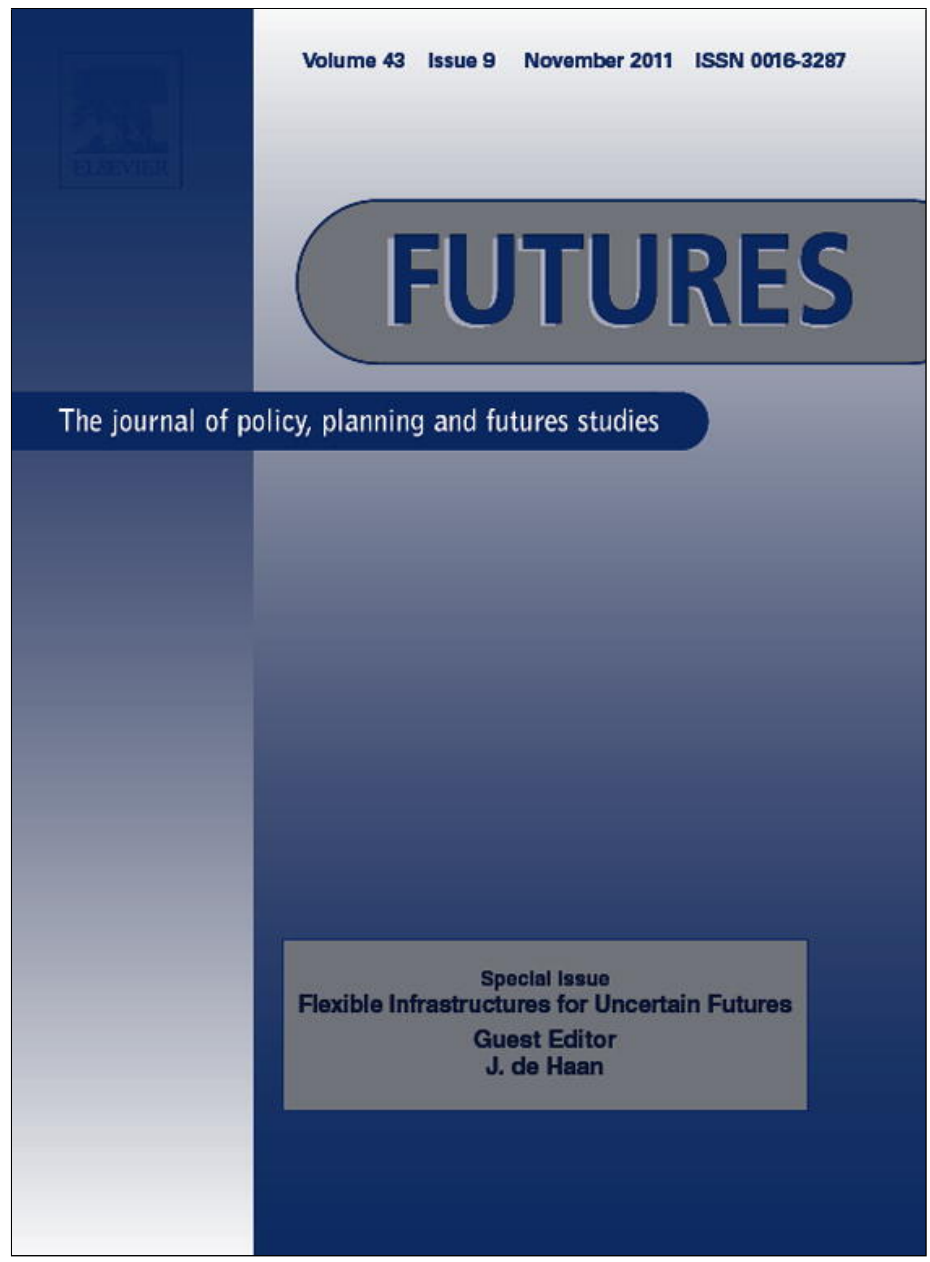

This article appeared in a journal published by Elsevier. The attached copy is furnished to the author for internal non-commercial research and education use, including for instruction at the authors institution and sharing with colleagues.

Other uses, including reproduction and distribution, or selling or licensing copies, or posting to personal, institutional or third party websites are prohibited.

In most cases authors are permitted to post their version of the article (e.g. in Word or Tex form) to their personal website or institutional repository. Authors requiring further information regarding Elsevier's archiving and manuscript policies are encouraged to visit:

http://www.elsevier.com/copyright 


\title{
Buying real options - Valuing uncertainty in infrastructure planning
}

\author{
Paulien M. Herder ${ }^{\mathrm{a}, \mathrm{b}}$, Jeroen de Joode ${ }^{\mathrm{a}, \mathrm{c}}$, Andreas Ligtvoet ${ }^{\mathrm{a}, *}$, \\ Sigrid Schenk ${ }^{\mathrm{a}, \mathrm{d}}$, Poonam Taneja ${ }^{\mathrm{e}}$ \\ ${ }^{\text {a }}$ Faculty of Technology, Policy and Management, Delft University of Technology, Jaffalaan 5, Delft, The Netherlands \\ ${ }^{\mathrm{b}}$ Next Generation Infrastructures Foundation, Jaffalaan 5, Delft, The Netherlands \\ ${ }^{\mathrm{c}}$ Energy research Centre of the Netherlands, Radarweg 60, Amsterdam, The Netherlands \\ ${ }^{\mathrm{d}}$ Rebel Group, Wijnhaven 3-O, Rotterdam, The Netherlands \\ e Faculty of Civil Engineering and Geosciences, Delft University of Technology, Stevinweg 1, Delft, The Netherlands
}

\section{A R T I C L E I N F O}

Article history:

Available online 17 June 2011

\begin{abstract}
A B S T R A C T
For the last two decades real options thinking has been heralded as a new approach for handling uncertainty in investment decisions. However, application of the approach in infrastructure investment decision-making is negligible thus far. In this contribution we address the question: what are the barriers for the implementation of the real option approach (ROA) in practice? We focus on the experiences in several infrastructure-bound sectors: spatial planning and transport, ports, and energy.

We conclude that the ROA maturity levels of these different sectors are quite different, and we ascribe these differences to the political setting, the institutional setting and the organisational flexibility of the sectors and their stakeholders. We suggest that the same issues apply to other advanced, quantitative methods.
\end{abstract}

(c) 2011 Elsevier Ltd. All rights reserved.

\section{Introduction}

Decisions about large scale (infrastructure) projects have to be taken while future developments are uncertain. As these projects are implemented over several years, sometimes decades, there are many factors that can change in the meantime: technological advances, changing stakeholders, political shifts, and economic fluctuations. It is believed that in recent times these uncertainties have only increased [1], making decisions even more risky.

As the costs involved are high and these projects are (nearly) irreversible - in the sense that abortion would be nearly as costly as finishing the installation - it is not surprising that project managers want to plan ahead and identify all risks imaginable. Some say that it is in the nature of the engineer to attempt to design artefacts that withstand the test of time [2]. A fundamentally different approach would be, rather than investing efforts to reduce the different components of uncertainty, to develop better ways to live or co-exist with uncertainties and risk. The key words in this approach are: resilience, flexibility, and robust response strategies $[3,4]$.

In line with the latter approach, the idea that investment decisions for large scale projects can be treated like options in a stock market was conceived more than 30 years ago. Dubbed 'Real' Options Approach (to emphasise that the approach deals with tangible assets), this approach has received ample attention in both financial and engineering literature [5-8]. While real options analysis was purportedly coming into wide use in the year 2000 [9], we notice that a decade later this take-off phase has not led to wider deployment of the method. Certainly in the public sector the use of real options approach (ROA) in

\footnotetext{
* Corresponding author. Tel.: +31 152785749; fax: +31 152783422.

E-mail address: a.ligtvoet@tudelft.nl (A. Ligtvoet).
} 
practice seems to be limited compared to the private sector. ${ }^{1}$ In this contribution we aim to gain insight into the reasons for this phenomenon.

Focusing on investment decision-making by public or semi-public actors in infrastructure-bound sectors and network industries, we aim to answer the following questions: Why is it that while real options analysis shows great potential and superior valuation in academic literature, it is not widely implemented in the practice of infrastructure projects valuation? What are the barriers for the implementation of a real option approach?

We tackle these questions by describing the decision-making environment in each sector and comparing experiences cross-sectorally. These experiences are placed in a framework based on available real options literature.

In Section 2 we present the theoretical value added of using real options in investment decision-making where large uncertainties are involved, and review the barriers to the implementation of the real option approach. In addition, we present and discuss the key players in the network of actors involved in the investment decision-making process in infrastructures. Section 3 describes practice in a number of infrastructure sectors: spatial planning and transport, ports and energy. For each sector we provide some exemplary applications of the real option approach and reflect on possible differences in the investment decision-making environment. Finally, Section 4 draws conclusions with respect to the use of the real option approach in physical infrastructure-bound sectors.

\section{Value added of real options}

\subsection{Real options in theory}

ROA was derived from financial options valuation. It therefore works best under conditions that resemble (perfect) financial markets: perfect information, perfect competition (no arbitrage), liquid assets. Basically, valuation can work on real assets provided that there is some sensible information about expectations and uncertainty. The hard part of valuation in the real world is that there often is very limited information on long-term uncertainty.

According to its proponents, the real options approach entails a new way of thinking about risk and valuation of choices in asset management. There are two main elements that underlie real options thinking [10]: the first half is about recognising that uncertainty provides investment opportunities and the second is about how options are valued. In the implementation of our framework we therefore distinguish between the first, strategic consideration of flexibility and the second, valuation of flexibility.

The strategic consideration relies on the insight that uncertainty is not a risk, but an opportunity. Several authors [10,11] claim that in the engineering world the practice is to design projects according to strict standards and a meticulous eye for detail. A set of assumptions is made and the optimal solution is construed within the bounds of time, money and manpower. Once this optimal solution is found, any disturbance in the outside world that negates one or more assumptions that lead to optimality, is considered a risk - in this context something negative.

The power of ROA lies in recognising that projects are processes that take place over time and that can be subdivided into smaller components: building a road, a factory, or a harbour in reality is not about a one-time go/no-go decision, but about dealing with developments along the way and adjusting to set-backs or opportunities that emerge. The fact that 'real' projects do not have to be one-shot decisions is of value to the decision-maker: in adverse situations the project may be reduced in size, whereas in favourable conditions the project may be enlarged. Such flexibility has been labelled as options on projects. The artefact that is being designed and built in the project can also be made adaptable during its lifetime, after project closure. For example, the foundations of a building have been over-designed to allow for an extra floor when more capacity is needed in due time. This has been labelled as options in projects [2]. ROA therefore promotes flexibility to deal with new situations. There are several real options that have been developed that might lead to flexibility:

- Option to defer: What uncertainties are relevant for this project? Could it be interesting to wait and invest later?

- Option to expand/contract: What is the minimum and maximum scale of the project? Is it possible to develop a more flexible scale which makes it possible to extend or contract operations in the future in the face of uncertainty?

- Option to shut down temporarily: Are continuous operations always required? Can an option to shut down temporarily be built in?

- Option to abandon: Is it at any point in time possible to abandon the investment?

- Option to grow: Is it possible to phase the project in smaller parts and delay part of the investment?

- Option to switch: What are the main inputs and outputs of this project? Is it possible to accommodate multiple inputs or outputs so that it is possible to switch later?

The strategic approach is really about promoting strategic insight and as such is very valuable, but probably not unique as a theory. What makes the whole approach interesting is by making value concrete: coupling it to valuation theory that is used in financial markets. Luehrman [12], for example, describes the analogy between an investment opportunity and a

\footnotetext{
1 This pattern seems to follow that of other financial-economic insights, such as valuation techniques like discounted cash flow analysis (DCF). It was met with great scepticism and also took over 30 years to get a foothold before evolving into standard practice.
} 
financial call option. The value of a project can be calculated by referring to comparable assets that are traded. Thus, subjective appraisal can be avoided and projects can be evaluated and compared on more objective grounds.

Although Black and Scholes [5] are often cited when talking about ROA as a valuation technique, the assumptions they make for calculating the options value do not map very well with complicated investment decisions. In options where different uncertainties play a role and where the option may be exercised at different times, different approaches are required. Trigeorgis [13], for example, linked option valuation to decision tree analysis. This method uses a discrete time process. For each period, an upside or downside movement of the value of the underlying asset takes place. The tree can take up compound options and multiple decisions and is therefore very useful for real option analysis, because it is flexible to simulate unique investment opportunities. Another approach to evaluating real options is based on Monte Carlo simulation models: by rolling out thousands of possible paths (due to uncertain factors with given or estimated probability distributions) from the present to the final decision date, the expected optimal investment strategy can be determined and the expected pay-off calculated. De Neufville et al. [11] have made a case to simplify real option valuation by promoting a 'spreadsheet approach'. This valuation method aims to avoid complex financial procedures and to use available data.

\subsection{Actor networks}

To be able to compare experiences in the different sectors, we will be more specific about the different actors involved and their interests. It is clear that there are sectoral differences with respect to the decision-making environment, but we assume the following non-exhaustive list covers the main actors:

- the project initiator, depending on the sector, is either a public or a private party (e.g. the Ministry of Transport, Port Authority). The main interest of this actor is to finalise the project within a specified time-frame;

- the financier is the provider of capital (e.g. Ministry of Finance, or local authority). Their main interest is to do the project within budget restrictions;

- the controlling authority (e.g. the National Bureau of Economic Research) is focused on doing a sound economic evaluation of the project ex ante - this will have to clarify to some extent whether the costs weigh up to the benefits;

- the political level/decision-maker in (semi-)public infrastructure projects is interested in supporting those projects that are in line with their electoral promises and/or success;

- the end-users are interested in having access to an infrastructure of appropriate quality at a bearable cost;

- the tax payer/general public's main interest is to support projects that are economically and socially sensible.

From the short descriptions it is clear these actors' interests may be aligned, but this certainly will not be the case all of the time. Furthermore, whereas the first three roles (or maybe even the first four) may be summarised as 'government', the involved people and departments are often different. Thus, ROA expertise that is available in one department may not at all be accessible to other departments. Each of the actors mentioned above is therefore a 'client' of ROA expertise.

\subsection{Reasons for not adopting real options}

There can be several reasons for real options not being taken into consideration. In the following paragraph we investigate a range of arguments (part of which are given by the scarce literature on this topic) and later apply them to a number of illustrative cases. We will refer to policy makers or decision-makers as clients, while we refer to those knowledgeable about ROA as experts - they could be academics, consultants, or in-house experts or advisors of the client.

Problems of reputation: The first type of reputational problem is quite simple: there is none. It could be the case that while academics have been developing ROA, there has been little or no effort to disseminate the new findings. In that case, the client will have to be convinced of the method itself as well as its applicability to their situation. A more difficult problem arises when the method does have a reputation, but a bad one. The 2008/2009 economic crisis may have adversely influenced the reputation of 'complex' financial calculations. Possibly clients have heard of or read about examples of cases that have not delivered according to expectations. They may even have first-hand experience of ROA not living up to its promise. Finally, the procedures and way of thinking advocated in ROA might already be known in the organisation, but called differently.

Problems of capacity: The most difficult situation would arise if the decision-maker does not understand the (essence of the) method proposed [14]. In such a case, trust in the expert becomes essential. A more likely situation is that the expert can convey the gist of ROA, but that the organisation is constrained in a number of ways: available data, quantity of personnel, quality of personnel, time and money. Some of these are obviously interlinked. The lack of data might be solved, but the costs could be prohibitively large. If the personnel is already short on time, it will be difficult to burden them with a new approach or additional data gathering activities. Also, the personnel may not have the required skills to perform an ROA, so that external experts are needed. If the client is not convinced of the additional benefits of the analysis, the shortages in capacity are unlikely to be solved.

Problems of decisiveness: A further reason why the real options approach could be less desirable than 'plain old decisionmaking', is that real options are not decisive. What we mean is that they allow for flexibility, but at the cost of additional decision-making overhead. Without ROA the situation is simple: a project is either started or not. But ROA requires constant 
monitoring and review of the options. In other words, flexibility and options cost attention and computing power. Furthermore, decision-makers are afraid that a change of path in a political context may signal failure [15].

Problems of lock-in: During their operation, organisations acquire a certain routine, a certain way that things are done. Members of the organisation are dependent on the historical path the organisation has taken, which can relate to people employed, technologies and rules adopted, up to the long-term strategy. If the client is used to a certain methodology that has worked until now, it may be difficult to accept new approaches to the same problem. The organisation thus experiences so-called 'lock-in' [16-18]. As it becomes nearly impossible to switch from the old approach to the new approach with only implementing a few additional steps ('incrementalism'), the envisioned change becomes a revolution instead of an evolution.

Problems of compound uncertainty: Related to both the problem of capacity and mismatch is the problem of compound uncertainty. If an organisation has to rely on real options, it is probably because it faces some future uncertainty. One could argue that in these situations of uncertainty, decision-makers would shy away from adding more uncertainty by introducing an approach that they do not understand and for which the require outside expertise. Van de Riet [15] points out that decision-makers require unambiguous strategies in case of an unclear future.

Problems of applicability: The barriers listed above all suggest that ROA is a valid approach given conditions that resemble (perfect) financial markets: perfect information, perfect competition (no arbitrage), liquid assets. However, the more fundamental question is whether ROA assumptions hold in situations where 'real' assets are valued. Lander [14] as well as Wang [19] suggests that either the modelling assumptions are violated during real applications or that the method requires assumptions that limit the scope of applicability.

\section{Sectoral analysis}

Financial economic analysis has evolved from break-even analysis to net present value (NPV), to more sophisticated ways of valuing risk. These tools have initially been developed for financial markets and were later modified to be applied in 'real' markets. With some time lag they were finally introduced in public sectors. In the following section we discuss the actual and potential application (barriers and incentives) in a number of infrastructure-bound sectors.

\subsection{Spatial planning and transport infrastructure}

\subsubsection{Characteristics and governance}

Spatial planning and transport infrastructure includes new development or redevelopment of locations for either living, working, recreation, nature or a mix of these. Investments may include, for instance, real estate, road, rail or waterway infrastructure. These are usually irreversible investments with a high degree of uncertainty, that stems from the level of demand for real estate. Typically, these investments involve a variety of public actors, including ministries and local authorities. As it is taxpayers' money that goes into these projects, it is not only the financial value that matters but also the societal value.

In infrastructure and spatial development projects, economic valuation in the Netherlands is done in accordance with cost-benefit analysis guidelines: the OEI-guidelines [20]. These guidelines must be followed for all infrastructure projects above a certain level of investment.

These guidelines contain a description of valuation of flexibility using real options analysis. The document contains an example of a port expansion using a decision tree valuation of flexibility. The Dutch Bureau of Economic Research (CPB) states in these guidelines: "Flexibility in design and phasing of a project make it easier to adapt to future developments and reduce risks resulting from incorrect decisions. Due to the uncertainty over future circumstances, it can be judicious to keep certain options open until there is more clarity. The real option approach offers a framework for such strategic decisionmaking."

\subsubsection{Implementation and barriers}

Problems of lock-in: Ever since the notion of flexibility was introduced in the reported documents, mainly the CPB (Dutch Economic Bureau) and KIM (Knowledge Institute for Mobility Policy) have been studying the issue of flexibility. However, in practice the application of real options valuation is very limited. There seems to be agreement by several institutions and political committees on the added value of the real options approach, but there is a lack of a practical tool kit to assist project managers and decision-makers in specific projects. Other standard practices that poorly match (the implications of) real options are budgetary rules and standard contracts.

Infrastructure and spatial development projects also need to go through procedures that provide the necessary legal basis, such as an environmental impact assessment procedure that aims at fixing the scope of the project step by step. Decision criteria are not only economic, but also focus on factors such as environmental effects. The fixing of the scope conflicts with a flexible approach, which means keeping several options open and possibly changing the scope in the future. Infrastructure projects and spatial development projects are often realized in public-private partnerships, for instance in design-build-finance-maintain contracts. These are long term contracts that currently have no provisions for flexibility.

Problems of reputation: There are several examples in academic literature for applications of options analysis in spatial and infrastructure projects. Probably one of the first applications is that of the Tagus river bridge in Portugal [21]. The original 
design of the bridge, constructed in 1966, constituted of a single deck four-lane road. In the original construction future expansion was made possible by using a stronger structure. In 1993 traffic rates had increased so that it was attractive to exercise the option to expand. The bridge was expanded with two road lanes and a railroad deck. This is also an example that shows that at the time, without the use of real options, common sense has made the project organisation include flexibility in their project.

In spatial development projects, applications are mainly found in the real estate part of the project. Examples are found in [22], who apply real option theory to real estate development in Amsterdam, called the Zuidas. The most important uncertainty that real estate developers have to deal with in this project is vacancy risk of offices and homes. By calculating different scenarios (for instance: transformation from home to office after 2, 4,6 or 8 years) it is possible to gain insight into optimal timing of the options. Consequently, academics show that there are opportunities for option valuation in this sector. However, there is a lack of real life examples where options valuation was actually included in decision making. This results in a lack of reputation.

Problems of capacity: Real options method requires quality data on uncertainty and cost of flexibility. These numbers can be difficult to estimate for infrastructure projects. In (road and rail) infrastructure, the main uncertainty is (road and rail) user value and rail revenues. In the Netherlands the road user pays a fixed-price tax independent of actual use. Rail users do pay a user-dependent fee, however, this is heavily subsidized. Consequently, price setting is heavily distorted by government intervention and this influences the demand curve. These aspects make the 'market' for road and rail use quite different from, say, the market for stocks in the financial market.

Problems of compound uncertainty: Models have been developed to estimate road and expansion of road or rail capacity. These models have great difficulty in predicting actual use of road or rail facilities (see e.g. [23,24]). Whereas this aspect makes it difficult to find the necessary data for real options analysis, it stresses the importance of the analysis as well. Note that the value of flexibility rises with uncertainty. Real options method also implies that, if the flexible implementation of the project turns out to be economically optimal, part of the investment decision may be passed through to the future. In a political context, this flexibility can be understood by adversaries as failure to make choices or fear of making choices.

There is a special category of the most expensive infrastructure projects called 'mega projects'. Examples of these projects are the Betuweroute freight rail line from Rotterdam to Germany, the High Speed passenger rail line from Amsterdam to Antwerp, the North-South metro line in Amsterdam and the Amsterdam Zuidas (combined road, rail, and metro infrastructure, and spatial development project). All of these projects are politically very sensitive subjects and 'keeping options open' to make an optimal decision somewhere in the future does not go well with the lengthy political process. Also, many mega projects have nearly always resulted in major budget overruns. This means that politicians are becoming suspicious of economic valuation tools and as a reflex tend to favour 'proven technology/methods' over new complex methods that result in a higher project value. This limits the room in a specific project to introduce both flexibility and the real options valuation method.

\subsection{Port infrastructure}

\subsubsection{Characteristics and governance}

The provision of port services entails large fixed costs and low marginal costs. A relatively large, minimum initial capacity of basic infrastructure is required for technical reasons. The infrastructure is frequently indivisible and, as a result, increases in infrastructure capacity can only be realized in 'quantum chunks'.

Both initial construction and port expansion require large amounts of capital. As a result, the need to develop basic port infrastructure (for example, sea locks, breakwaters, quay walls, terminal areas and connections) all at once creates large capital operating losses and foregone investment opportunities as a result of underused capacity during the earlier phases of a project's life cycle. The life span of port infrastructure projects mostly exceeds the time horizon acceptable for private investors and commercial banks.

Countries organize port management in a way that is appropriate to their general system of government. From a formal point of view, at least four different types of port administration can be singled out [25]: state-administered ports, municipally-administered ports, autonomously administered and privately managed ports. In many ports today, the public sector mainly acts as planner, facilitator, developer, and regulator while providing connectivity to the hinterland, whereas the private sector acts as service provider, operator, and sometimes also developer.

\subsubsection{Implementation and barriers}

Ports depend on trade for their existence. This trade is very unpredictable in present times (due to trends in globalization, liberalization, rapidly changing technologies, and emerging economies), which makes investment in port infrastructure highly risky. Flexibility is increasingly cited as a key goal for dealing with uncertainty in the decision-making related to design, planning and investment in port infrastructure systems [26]. Existing applications of real options in the port sector include:

- timing or phasing of investments in infrastructure and superstructure;

- building in flexible options in the port infrastructure, i.e. extra investments that can be utilized at a later stage, such as a deeper quay walls for larger future ships and stronger structures for greater loads in the future (also called building in margins); 
- using flexible and innovative infrastructure solutions (instead of traditional solutions) and justifying the extra cost by means of a real options analysis;

- considering options such as delay and abandonment, or taking advantage of new opportunities and using real options analysis for project evaluation;

- testing models or carrying out simulation exercises to reduce risk and having to write off expensive designs and equipment;

- investing in multi-purpose infrastructure (quay walls, buildings) or investing in more general-purpose resalable equipment.

In port planning uncertainty and flexibility are hardly taken into consideration. Master plans often include single point forecasts of future demand that are used to create a land-use plan for the future development of the port for a time horizon varying from 5 to 50 years. Over a long time horizon, this basically amounts to ignoring uncertainty. Standard design practice involves deterministic requirements laid down in a 'terms of reference' document together with a list of norms or guidelines which a designer must use as basis for his infrastructure designs. This practice leaves no margin for flexibility. In the execution of the project, flexibility is generally seen as a threat to delivering the project on time and within budget. In order to maximise efficiency, projects needs to be clearly defined in the front-end phase and executed according to the plans. Finally, in project evaluation the port sector is also very conservative: a cost-benefit analysis (CBA) based on discounted cash-flow (DCF) is employed as a decision-making tool for projects exceeding a certain monetary value. Uncertainty is taken into account by considering a certain variation around the base case net present value (NPV) (thus an optimistic and pessimistic scenario). The decision to invest or not to invest is generally based on the base case scenario (except for situations where the pessimistic case shows very bad results).

As an exception there is a prime example of real option application in the Port of Rotterdam. The Port Authority is responsible for the construction of Maasvlakte 2, an ongoing large-scale port expansion project by creating new land in the North Sea. A special project group has been set up within the port organization for this purpose. The group has chosen for a phased construction, which gives it the option to abandon the following phase of the project, and avoid a part of the capital expenditure if the market deteriorates. This is a prime example of real options application, and shows the willingness of a newer organization to apply new methods and techniques for investment decisions.

The concept of uncertainty is being increasingly mentioned in the port sector but flexibility and real options analysis have not gained favour in practice. The reasons for resistance to real options discussed in Section 3.1 also apply to most port projects. Some other reasons for the unpopularity or ROA are listed below:

Problems of reputation: Tools such as probabilistic cost benefit analysis, decision trees or ROA seem to have no reputation in the conservative port sector. Due to increasing uncertainty, the importance of flexibility is being increasingly recognized (as illustrated by the Maasvlakte 2 Port expansion project) but real option analysis for project evaluation is relatively unknown.

Problems of lock-in: Designers are not used to thinking in terms of uncertainty and flexibility. They think they adequately consider uncertainty when they follow the requisite design standards wherein safety factors to be incorporated in their designs are prescribed. Although alternative design options are investigated in every project, the traditional, mostly low-cost alternative is opted for, due to a lack of long term vision which involves a life cycle perspective and long term uncertainty considerations. Because designers operate within engineering 'silos', they do not consider how other system components might affect the overall economic value of the system [11].

Project appraisal is mostly carried out at the feasibility stage (mostly on the basis of a concept master plan) while technical design of port infrastructure is carried out at a later stage, almost always by a third party (consultants or advisors). The increasing popularity of various forms of design and construct contracts is reinforcing this trend. The motivation of the third party is generally limited to looking for an adequate and reasonably priced design alternative that meets the specifications, and flexibility is not high in the list of objectives. Moreover, a flexible option identified and incorporated in the technical design stage cannot be included in the initial project evaluation.

\subsection{Energy infrastructure}

\subsubsection{Characteristics and governance}

Physical infrastructure required for the delivery of energy to final consumers exhibits varying degrees of irreversibility and possible alternative uses, and hence make an interesting potential application field for real options. The real value of infrastructures is derived from the demand for infrastructure services, which in turn is dependent on the demand for energy (i.e. the commodity natural gas, electricity).

The lifetime of assets in the energy sector varies largely, starting with about 7-10 years for some electricity generating wind turbines to about 40-50 years for pipeline networks.

As in other sectors, one of the fundamental uncertainties in the energy sector is the future demand for energy (infrastructure) services. The future demand for energy is generally less uncertain than demand for specific energy carriers such as coal, natural gas, and hydrogen. Energy carriers face different competitors in the various end-user sectors. In the transport sector oil-based fuels dominate, while competition on the electricity market is between traditional fossil fuels and 
emerging renewable-based technologies. In addition, demand uncertainty on an individual energy carrier basis is dependent on uncertain political conditions and restrictions. A stringent allocation of CO emission rights in the future can largely influence the value of natural gas and coal assets. The same holds for possible research and development support for CO capture and storage technologies. Another example is the public acceptance of nuclear-based electricity generation. Intertwined with the above discussion is the fundamental uncertainty with respect to technology development, causing uncertainty for energy (infrastructure) services on the demand-side.

Before addressing some real option implementations in energy infrastructure investment we need to devote some words to energy infrastructure governance. Since liberalisation of energy markets (in Europe at the end of the 1990s) the extraction and sale of natural gas, and the generation and sale of electricity are characterised by competition. Before liberalisation, large vertically integrated electricity or gas companies controlled and planned the complete value chain, usually backed by strong government involvement. Basically system costs were socialised and risks associated with investment passed through to end-consumers. With the introduction of competition (and possibly bankruptcy) the risk position of energy companies was changed. However, liberalisation of the energy sector did not automatically induce privatisation of energy companies. To varying degrees across the EU (regional and local) governmental bodies retained company shares. The 'natural monopoly' parts of the energy chain, however, were not liberalised and remained regulated. The provision of electricity network and gas pipeline services was deemed impossible and undesirable in a competitive environment. Electricity and gas network companies remain regulated with respect to access and tariff conditions, with regulatory authorities de facto approving cost structures and investment conditions. This implies that they have a different risk perspective compared to companies in the wholesale or retail markets.

\subsubsection{Implementation and barriers}

In the electricity generation sector it is quite common to include modular decision-making in generation asset investment in order to deal with demand uncertainty. Real options are also used to counter uncertainty with respect to the availability and price of fuels for electricity generation. Security of supply and development of price differentials in particular are drivers for investing in multi-fuel electricity generation facilities. In general, electricity generation companies have been rather quick in realising the added value of real option valuation in asset and risk management, in contrast with companies in the network business [27]. An application example in the US is related to the sale of CHP units (also known as cogeneration): "Competitors outbid utilities often for the purchase of cogeneration plants. In these cases, the competitors had a better understanding of the value of real options. As a result, they had valued the plants significantly higher while utilities had relied in traditional NPV analysis" [28].

A possible explanation for the limited application in electricity networks is given in [29]. The authors construct an analytical framework for decision-making on electricity network investment that includes option valuation of uncertain demand and the option value of early deferral. They note that coordination between generation and transmission investment is crucial for the value of the investment. Since this coordination is no longer undertaken by a 'central planning entity' in liberalised electricity markets this could remain a possible barrier in real option implementation.

Something that possibly holds in general for regulated networks is the fact that the specific design of regulation (i.e. obligations, rules on cost and risk allocation) prevent implementation of the real options approach at firm level. At the level of advice to policy-makers an interesting report was published on realising the Dutch government's ambitions to realise large wind parks at the North Sea [30]. In judging whether such a realisation could be beneficial for society as a whole, a costbenefit analysis was executed in line of the earlier mentioned OEI guidelines. In this exercise a real option approach was implemented implicitly by addressing several future scenarios with respect to the stringency of EU climate policy (i.e. influencing the price of $\mathrm{CO}$ emission rights), and simulating a number of scenarios where wind parks are realised gradually, with phased investment.

Problems of reputation: Analysing actual and potential applications of ROA in energy infrastructures requires a distinction between market-based and regulated activities. Investment in generation assets generally occurs within a free market environment whereas investment in infrastructure assets is regulated. Real options application in investment decisionmaking in the regulated infrastructure sector add another actor that in some way needs to approve of the ROA: the regulatory authority. Compared to the unregulated investment projects on the generation side there is yet another actor to 'win over'. But exactly this public actor might have been subjected to bad ROA reputation in infrastructure investment projects undertaken under government control. The additional layer of regulatory confirmation also makes real options adoption in infrastructure investment more prone to capacity problems. The energy regulatory authority may not have the capacity to sufficiently grasp the complexity of real options implementation.

Problems of lock-in may apply to ROA implementation in energy infrastructures as well. Not to long ago the energy system was based a vertically integrated businesses with strong government backing and a large degree of central planning. The introduction of market forces began only in the 90s. With this introduction, spot and forward markets emerged and with it different types of financial instruments. Actors in the energy system had to adapt their technologybased thinking with central planning as coordination mechanism to more market-based thinking with market prices being the main coordination mechanism. The application of a typical financial tool as ROA is not straightforward in organisations that are possibly not fully adapted yet to the new market paradigm. In other words, lock-in problems may still prevail, probably more so in the regulated parts of the industry (the infrastructure part) than in the unregulated parts (generation, retail). 
Another possible relevant factor is ownership. Whereas energy production companies have been largely privatised, regulated infrastructure companies have largely remained under public ownership. Private investors may have more affinity with financial decision-making with complex instruments than do public investors. Although some sporadic publications exist on the use of ROA in the oil exploration and production industry [31,32] that would support this idea, the actual use of ROA turns out to be limited. This is due to long-established ways of project valuation in which the main goal is to minimize investment cost regardless of anything. The associated incentive systems on project managers enhances this idea.

\section{Conclusions}

Looking at the sectors mentioned above, we found the following generic types of problems for implementation:

- The applicability of the original methods becomes ever more shaky when moving from the financial markets, to real markets, to 'hard' and finally 'soft' public sector markets. The more the investments deal with 'unique' products for which there are no alternatives available on the market, the more difficult it is to apply the original ROA valuation techniques. Therefore, it requires time to fit method and investment project.

- Many infrastructure settings resemble a non-competitive, monopolistic environment. This results in less incentive for the project initiators to quickly absorb best-practices, such as real options, than would be expected in a competitive setting.

- Most sectors include a variety of public actors or stakeholders, which is different from most commercial enterprises. This multi-agent setting complicates the implementation of flexibility. Decision-making involves a lot more than just a board meeting; it is often a long process which could also include political trade-offs and stakeholder consultations.

- The public setting also results in a principal-agent problem. Optimal investment decisions are best made when the one who pays, decides and reaps the benefits are combined in one person, or board. In a private company, this setting can be quite closely resembled by managers, holding shares and receiving bonuses. In a public setting, these roles are separated much more. The one who pays is most likely the taxpayer, the one who decides is politics and the ones who reap the benefits are the users.

However, the most prominent problem seems to be the problem of lock-in. Rather than blaming the capabilities, decisiveness, reputation or trust in (semi-)public infrastructure settings, project initiators and decision-makers are bound by the political setting, the institutional setting, and the organisational flexibility.

Political setting: In spatial planning and transport infrastructure it is observed that the political sensitivity of projects is generally high. Ministries want to realize projects but are bound by many procedures and laws. This high political sensitivity seems less in the port and energy infrastructures. A ROA approach does not suit a highly sensitive political context due to its seemingly complex nature and due to the asymmetric cost and benefit distribution, i.e. not many political leaders are willing to bear the cost for a possible benefit in someone else's future.

Institutional setting: The competitive pressure in the private sector makes it more likely to adopt new methods: a company cannot afford to be outsmarted by a competitor by structurally underestimating risk. The public sector, on the other hand, needs to be predictable and transparent. Each new method has to be approved by many layers of management and controlling agencies, and finally explained in such a way that the general public can grasp the essence of the method. This creates a hesitation to apply new, more complex methods. The energy sector is illustrative for organizations that are in deregulated and liberalized and privatized markets (oil, gas); the use of ROA is much more accepted than in the regulated markets (electricity). Also, the public sectors of ports and spatial planning are lagging in the ROA implementation. This leads to a tentative conclusion that public, regulated sectors are less able to adopt ROA than the private sector, due to their incentive structures and 'business' models (regulation, profit/non-profit).

Organisational flexibility: The port infrastructure, owned and operated by one actor, showed a remarkable difference between its embedded project organisation (charged with executing large projects) and its standing organisation. The flexibility and dynamics in the organisation and its personnel that are inherent to a project organisation were reflected in the higher level of ROA adoption as compared to the standing organisation.

Buying real options in the three sectors that were analysed in this paper is not always possible. The different barriers that were identified play a role in each sector, but organisational, institutional and political lock-in seem to be the most prominent. Unfortunately, bringing down the lock-in barrier would require much more than learning ROA tools and methods: it would require a systemic shift. It is plausible to assume that other innovative but complicated (quantitative) methods for dealing with future uncertainty face similar barriers.

\section{References}

[1] Z. Sardar, Welcome to postnormal times, Futures 42 (2010) 435-444.

[2] R. de Neufville, Real options: dealing with uncertainty in systems planning and design, in: 5th International Conference on Technology Policy and Innovation, Technical University of Delft, June 2001.

[3] A. Klinke, O. Renn, A new approach to risk evaluation and management: risk-based, precaution-based, and discourse-based strategies, Risk Analysis 22 (6) (2002) 1071-1094.

[4] S. Macgill, Y. Siu, A new paradigm for risk analysis, Futures vol. 37 (December) (2005) 1105-1131.

[5] F. Black, M. Scholes, The pricing of options and corporate liabilities, The Journal of Political Economy 81 (May-June) (1973) 637-654.

[6] A. Dixit, R. Pindyck, Investment Under Uncertainty, Princeton University Press, 1994. 
[7] R. de Neufville, Uncertainty management for engineering systems planning and design, in: 1st Engineering Systems Symposium, Cambridge, MA, USA, Massachusetts Institute of Technology, 2004.

[8] T. Copeland, V. Antikarov, Real options: meeting the Georgetown challenge, Journal of Applied Corporate Finance 17 (2) (2005) 32-51.

[9] C.S. Park, H.S. Herath, Exploiting uncertainty - investment opportunities as real options: a new way of thinking in engineering economics, The Engineering Economist 45 (1) (2000) 1-36.

[10] M. Amram, N. Kulatilaka, Real Options, Harvard Business School Press, Boston, Massachusetts, 1999.

[11] R. de Neufville, S. Scholtes, T. Wang, Real options by spreadsheet: parking garage case example, in: Tech. Rep. Manuscript IS/2004/22436, Massachusetts Institute of Technology, Cambridge, MA, 2005.

[12] T. Luehrman, Investment opportunities as real options: getting started on the numbers, Harvard Business Review vol. 76 (1998) 51-66.

[13] L. Trigeorgis, S. Mason, Valuing managerial flexibility, in: E. Schwartz, L. Trigeorgis (Eds.), Real Options and Investment Under Uncertainty - Classical Readings and Recent Contributions, MIT Press, Massachusetts, 2001.

[14] D.M. Lander, G.E. Pinches, Challenges to the practical implementation of modeling and valuing real options, The Quarterly Review of Economics and Finance vol. 38 (1998) 537-567.

[15] O. van de Riet, Scenario analysis and the adaptive approach: superfluous or underused in transport infrastructure planning?, in: Conference on Building Networks for a Brighter Future, 10-12 November 2008, Rotterdam, The Netherlands, 2008.

[16] F.B. Simon, Einführung in die systemische Organisationstheorie, Carl-Auer Verlag, Heidelberg, 2007.

[17] J. van den Bergh, A. Faber, A. Idenburg, F. Oosterhuis, "Survival of the greenest - evolutionaire economie als inspiratie voor energie- en transitiebeleid," Tech. Rep. 550006002, RIVM, Bilthoven, The Netherlands, 2005.

[18] J.G. March, Exploration and exploitation in organizational learning, Organization Science vol. 2 (1) (1991) 71-87.

[19] T. Wang, R. de Neufville, “Real options 'in' projects," in: 9th Real Options Annual International Conference in Paris, France, 2005.

[20] C. Eijgenraam, C. Koopmans, P. Tang, A. Verster, "Evaluatie van infrastructuurprojecten, leidraad voor kosten-batenanalyse," tech. rep., Ministerie van Verkeer en Waterstaat en Ministerie van Economische Zaken, Den Haag, 2000.

[21] G. Gesner, J. Jardim, Bridge within a bridge, Civil Engineering 68 (1998) 44-47.

[22] SEO, "Opties op de Zuidas. Final report for the city of Amsterdam.," tech. rep., Stichting Economisch Onderzoek, 2006.

[23] B. Flyvbjerg, From Nobel prize to project management: getting risks right, Project Management Institute 37 (3) (2006) 5-15, 8756-9728/03.

[24] B. Flyvbjerg, N. Bruzelius, W. Rothengatter, Megaprojects, Risk: An Anatomy of Ambition, Cambridge University Press, Cambridge, UK, 2003.

[25] European Parliament, European Sea Port Policy. The European Parliament, Directorate General for Research, 1993.

[26] R. de Neufville, S. Scholtes, T. Wang, Valuing options by spreadsheet: parking garage case example, ASCE Journal of Infrastructure Systems 12 (2) (2006) $107-111$.

[27] B. Ramanathan, S. Varadan, Analysis of transmission investments using real options, IEEE Power Systems Conference and Exposition 1 (October-November) (2006) 266-273.

[28] C. Strickland, Extracting Hidden Value from Existing Assets: New Solutions in the Energy Markets, Lacima Group, presentation, 2005.

[29] G. Boyle, G. Guthrie, R. Meade, "Real options and transmission investment: the New Zealand grid investment test," Tech. Rep. ISCR-2006-02, New Zealand Institute for the Study of Competition and Regulation, February 2006

[30] A. Verrips, H. de Vries, A. Seebregts, M. Lijesen, “Windenergie op de noordzee: Een maatschappelijke kosten-batenanalyse.," tech. rep., Centraal Planbureau (CPB), Bijzondere Publicatie, vol. 57, 2005.

[31] A.G.Z. Kemna, Case studies on real options, Financial Management 22 (1993) 259-270 (Autumn)

[32] J.E. Smith, K.F. McCardle, Options in the real world: lessons learned in evaluating oil and gas investments, Operations Research 47 (1) (1999) 1-15. 